\title{
BMJ Open Emergency medical services responders' perceptions of the effect of stress and anxiety on patient safety in the out-of- hospital emergency care of children: a qualitative study
}

\author{
Jeanne-Marie Guise, ${ }^{1,2,3,4}$ Matthew Hansen, ${ }^{2}$ Kerth O'Brien, ${ }^{5}$ Caitlin Dickinson, ${ }^{6}$ \\ Garth Meckler, ${ }^{1,7}$ Phil Engle, ${ }^{8}$ William Lambert, ${ }^{4}$ Jonathan Jui ${ }^{2}$
}

To cite: Guise J-M, Hansen M, O'Brien K, et al. Emergency medical services responders' perceptions of the effect of stress and anxiety on patient safety in the out-of-hospital emergency care of children: a qualitative study. BMJ Open 2017;7:e014057.

doi:10.1136/bmjopen-2016014057

- Prepublication history for this paper is available online. To view these files please visit the journal online (http://dx.doi.org/10.1136/ bmjopen-2016-014057).

Received 1 September 2016 Revised 30 January 2017 Accepted 1 February 2017

CrossMark

For numbered affiliations see end of article.

Correspondence to Dr Jeanne-Marie Guise; guisej@ohsu.edu

\section{ABSTRACT}

Objective: Prehospital emergency medical services (EMS) providers report anxiety as the second most common contributor to paediatric patient safety events. The objective of this study was to understand how EMS providers perceive the effect of stress and anxiety on paediatric out-of-hospital patient safety.

Setting: This was a nationwide study of EMS providers from 44 of $50(88 \%)$ US states.

Participants: A total of 753 eligible EMS professionals, including emergency medical technicians, emergency department physicians and nurses (general and paediatric), and respiratory therapists who participate in out-of-hospital transports. Primary and secondary outcome measures: Outcomes included responses to: (1) clinical situations where heightened stress or anxiety was likely to contribute to safety events, (2) aspects of these clinical situations that cause stress or anxiety and (3) how stress or anxiety may lead to paediatric safety events. Results: EMS providers reported that the clinical situations where stress and anxiety were more likely to contribute to paediatric patient safety events were trauma, respiratory distress and cardiac issues. Key themes were: (1) provider sympathy or identification with children, (2) difficulty seeing an innocent child hurt and the inherent value of children and (3) insufficient exposure to paediatric emergencies. Conclusions: Caring for paediatric emergencies creates unique stresses on providers that may affect patient safety. Many of the factors reported to cause provider stress and anxiety are inherent attributes of children and therefore not modifiable. Tools that support care during stressful conditions such as cognitive aids may help to mitigate anxiety in the prehospital care of children. Further research is needed to identify opportunities for and attributes of interventions.

\section{INTRODUCTION}

Providing care during critical events is a recognised cause of provider stress, anxiety

\section{Strengths and limitations of this study}

- This is one of the first and largest studies of patient safety in the out-of-hospital setting.

- The survey's design promoted privacy, independence and candour in individual responses.

- This study was limited to the experience of US emergency medical response systems and since context varies throughout the world, it is possible that our results may not be generalisable to all countries.

and even post-traumatic stress disorder (PTSD) among hospital workers. ${ }^{1}$ Stress, anxiety and PTSD have also been reported among out-of-hospital personnel. ${ }^{2}{ }^{3}$ A recent systematic review and meta-analysis of PTSD in 28 studies of rescue workers worldwide estimated prevalence at $10 \%{ }^{4}$ Such factors have been associated with provider sickness, ${ }^{5}$ early retirement $^{6}$ and burnout. ${ }^{7}$

In the hospital setting, stress and personal factors have been demonstrated to play a role in medical errors and patient safety. For example, an Australian study found that over $60 \%$ of medication errors in a hospital-based pharmacy were due to personal factors such as stress. ${ }^{8}$ In the less controlled setting of out-of-hospital care of acutely ill patients, it is reasonable to expect that stress similarly affects performance and patient safety in delivery of care to critically ill children. ${ }^{9}$

We conducted a qualitative analysis of responses to open-ended questions in a large national survey of emergency medical service (EMS) providers to characterise their perceptions of the role that stress and anxiety may play in patient safety during the out-of-hospital emergency care of children. 


\section{METHODS}

\section{Study design and participants}

We conducted a qualitative content analysis of responses to three sequential electronic surveys of EMS providers across the USA. This study was conducted as part of a larger mixed-methods Children's Safety Initiative-EMS (CSI-EMS) study funded by the US National Institutes of Health (NICHD R01HD062478). The goal of the CSI-EMS is to identify, describe and classify the occurrence of safety events in out-of-hospital paediatric emergency care. The CSI-EMS includes: (1) focus groups; (2) a national Delphi study, on which the current investigation is based; (3) a chart review and (4) in situ simulation. ${ }^{10}{ }^{11}$ Participants were EMS professionals including: emergency medical technician-paramedic (EMT-P), EMT-intermediate (EMT-I), EMT-basic (EMT-B) and first responders as well as administrative leaders, emergency department physicians and nurses (general and paediatric), and respiratory therapists, professionals who provide care to out-of-hospital children's emergency transports (eg, ambulance transport and fire departments). These provider groups were selected based on each group having a unique perspective on paediatric EMS care and differing lenses for safety events. Participants were recruited through email lists of US EMS and emergency medicine specialty societies and professional groups, as well as through social media. Participants were excluded if they were younger than 18 years of age or failed to complete the demographics section of the survey. ${ }^{12}$ Participants who completed all three survey rounds were compensated for their time by being entered in a drawing for 1 of 10 tablet computers. ${ }^{11} 12$

\section{Survey design and content}

Survey questions included questions with structured and unstructured response formats. Demographic information was assessed, including age, gender, level of training, years of experience, full-time or part-time status, paid or volunteer work and the number of paediatric patients seen in the previous year. In order to achieve a rich understanding of the role that provider stress and anxiety may play on patient safety during the out-of-hospital response to children's emergencies, we followed a grounded theory approach of inquiry. We asked questions in an open-ended format to avoid imposing preset expectations on participants' input and to promote open learning from participants' own terms. All survey questions were developed through focus groups. ${ }^{10}$ We also conducted cognitive interviews to assess the face validity, clarity of content, instructions and usability of the survey ${ }^{11}{ }^{12}$ Subsequent survey questions were shaped by responses from the prior survey round.

In a standard Delphi procedure, experts respond independently of one another, thus reducing the biasing effect of particular group opinion leaders and group pressure. ${ }^{13}$ In the first survey round, participants were asked, "Based on your experience, how likely is each of the following to be an important contributing factor leading to safety events or errors in the prehospital care of children?." Participants rated the likelihood based on a 9-point Likert-type scale, ranging from 1 (not at all likely) to 9 (highly likely) for 75 potential contributors, including items such as lack of experience with paediatric airway procedures, paediatric-sized equipment availability and heightened anxiety when working with children. Results of the larger study have been previously published; ${ }^{11}$ notably, heightened anxiety when working with children was highly rated across all survey rounds as a potential contributor to safety events or errors.

In the second round, respondents were asked to describe up to three clinical situations where they felt heightened anxiety was likely to lead to patient safety events. In the third and final survey round, participants were asked to provide narrative responses to two complementary questions: (1) "We know from round 2 that trauma causes heightened anxiety. Please help us understand what aspects of trauma in children contribute to heightened anxiety in providers," and (2) "How can this anxiety lead to safety events or errors?"

All surveys were administered through an electronic web-based survey system (SurveyMonkey), and surveys were completed over a 1-year period between August 2011 and July 2012. Confidentiality of participant responses was emphasised in soliciting participants' candid viewpoints.

\section{ANALYSIS}

We adhered to methodologically sound qualitative research methods including following an iterative approach for data collection and analysis, independent reviews of texts, thematic coding by qualitatively trained reviewers and convergence of interpretation across a multidisciplinary team of researchers. ${ }^{14}$ Our analysis was guided by principles of grounded theory, in which an understanding of the concept of interest arises from the empirical data rather than from a priori hypotheses. ${ }^{15}$ Responses to open-ended questions were entered into NVivo9 software (QSR International, Cambridge, Massachusetts, USA). Two trained analysts independently reviewed responses to identify and code themes and subthemes. After a preliminary review of the data, the investigators developed an initial list of codes, which were modified and expanded as the analysis progressed. To ensure reliability of the coding structure, all themes and subthemes were reviewed with the larger multidisciplinary research team, which included hospital and prehospital EMS providers, EMS directors, EMS programme managers, physicians, quality and safety researchers, epidemiologists, a qualitative psychologist and a qualitative sociologist. Discrepancies between coders were resolved through discussion in the larger research team. 


\section{RESULTS}

A total of 753 eligible EMS professionals from 44 of 50 states $(88 \%)$ consented to participate in the study. A total of 722 participated in the first survey round, 614 (85\%) completed Round 2 and $492(68 \%)$ completed the final survey round. Table 1 describes characteristics of study participants. Approximately $80 \%$ of the sample comprised EMTs and paramedics. The proportions of professional groups varied $<2 \%$ across the three survey rounds.

Increased provider-level anxiety was perceived to be the second most common contributor to patient safety events when caring for out-of-hospital paediatric emergencies. The three clinical call situations where heightened anxiety was reported to be most likely to lead to safety events were: (1) trauma, (2) respiratory distress and (3) cardiac issues. Among those reporting a specific call reason, trauma and child abuse were commonly reported (107/271 (39\%) and 33/271 (12\%), respectively) as situations where paramedic anxiety could contribute to safety events. Table 2 presents six key themes with representative quotes for the ways in which providers reported that anxiety makes errors and patient safety events more likely.

The six most common themes that emerged to characterise providers' perceptions on stress and anxiety and how stress and anxiety affect patient safety were: (1) provider sympathy/identification with children, (2) difficulty seeing an innocent child hurt/inherent value of children, (3) insufficient experience/exposure, (4) family/bystander emotional responses, (5) children's emotional responses and (6) anxiety that the child's medical condition could rapidly deteriorate. Numerous EMS providers reported that they identified with injured or sick children, often associating them with their own children. EMS providers indicated that they felt this influenced their care and judgement. The second most common theme was the stress in knowing that an innocent life was at stake. Providers felt this created a sense of pressure around correct decision-making. The final theme, 'relative lack of experience with pediatric emergencies' has been the major focus of interventions until now. EMS providers reported feelings of intense pressure and inner dialogue as they are caring for a child.

We organised the themes from the qualitative analysis into an ecological framework to understand the contributors to provider stress and anxiety in the out-of-hospital care of children. Figure 1, which describes this framework, begins on the left with characteristics most central to the provider and expands to more distal influences. ${ }^{16} 17$ This framework distinguishes among characteristics of providers, paediatric patients (related to specific emergencies or inherent to childhood itself) and the family context, such as distressed parents who in some instances may contribute to safety events or errors in out-of-hospital care.

\section{DISCUSSION}

This qualitative analysis suggests that the inherent nature of children, compared with adult patients, is a key source of anxiety and stress for EMS providers when responding to an emergent call and that this anxiety is perceived to be an important contributor to patient safety events. Six major themes were identified for the specific ways in which paediatric patients cause stress or anxiety. Top of the list was sympathy/identification with the patient. Providers stated that they often saw their own children in the patient they were caring for and that this identification influenced their clinical

Table 1 Characteristics of study participants ${ }^{*}$

\begin{tabular}{llll}
\hline Participant characteristics & Round $\mathbf{1}(\mathbf{n}=\mathbf{7 2 2})$ & Round $\mathbf{2}(\mathbf{n}=\mathbf{6 1 4})$ & Round $\mathbf{3}(\mathbf{n}=\mathbf{4 9 2})$ \\
\hline Age & $41.7 \pm 10.3$ & $41.8 \pm 10.3$ & $42.3 \pm 10.3$ \\
Male & $438(60.7)$ & $368(59.9)$ & $301(61.2)$ \\
Have children & $558(77.3)$ & $459(74.8)$ & $372(75.6)$ \\
Provider type & & & \\
$\quad$ Paramedic & $367(50.8)$ & $316(51.5)$ & $254(51.6)$ \\
$\quad$ Advanced EMT & $50(6.9)$ & $39(6.4)$ & $31(6.3)$ \\
$\quad$ EMT & $159(22.0)$ & $129(21.0)$ & $99(20.1)$ \\
$\quad$ MD, DO & $82(11.4)$ & $70(11.4)$ & $64(13.0)$ \\
$\quad$ NP, RN, RT, LPN & $64(8.9)$ & $60(9.8)$ & $44(8.9)$ \\
Experience & & & \\
$\quad$ Years working in EMS & $16.8 \pm 9.4$ & $17.0 \pm 9.3$ & $17.1 \pm 9.2$ \\
$\quad$ Number of years at current level & $14.0 \pm 9.2$ & $14.0 \pm 9.1$ & $14.2 \pm 9.1$ \\
Geographic location & $244(33.8)$ & $213(34.7)$ & $165(33.5)$ \\
$\quad$ Urban & $226(31.3)$ & $183(29.8)$ & $145(29.5)$ \\
$\quad \begin{array}{l}\text { Suburban } \\
\text { Rural }\end{array}$ & $250(34.6)$ & $213(34.7)$ & $177(36.0)$ \\
\hline
\end{tabular}

${ }^{*}$ Values are presented as mean \pm SD for continuous variables and as number (\%) for categorical variables.

DO, doctor of osteopathy; EMT, emergency medical technician; LPN, licensed practical nurse; MD, medical doctor; NP, nurse practitioner; $\mathrm{RN}$, registered nurse; $\mathrm{RT}$, respiratory therapist. 
Table 2 Emergency medical services responders' perspectives on the contributors to stress, anxiety and safety events in the out-of-hospital emergency care of children

\begin{tabular}{|c|c|}
\hline Sympathy/identification with patient & $\begin{array}{l}\text { "Sympathy for the patient can cloud judgement" } \\
\text { " "For those of us that are parents, it is stressful to think about the possibility of being } \\
\text { one of our own children, making one have a heightened level of stress" } \\
\text { "If we are parents, we also may have a tremendous sense of identification fear/ } \\
\text { familiarity that can add to the anxiety level" } \\
\text { "Because of the emotional components: people see their children as being the } \\
\text { patient/family on scene causing stress we don't normally have" } \\
\text { "The 'what if that was my kid' questions causes distraction during care" } \\
\text { "Fear of similar injuries in own children is probably the largest factor. The apparent } \\
\text { fragility of children and the potential harm that traumatic injuries can impose might } \\
\text { also be a large factor" }\end{array}$ \\
\hline $\begin{array}{l}\text { Innocence of children/perceived } \\
\text { value of children }\end{array}$ & $\begin{array}{l}\text { "Children are different than adults in the simple fact that they are children who are } \\
\text { innocent and still have their whole lives ahead of them" } \\
\text { "Innocent life being damaged through no fault of their own, lack of experience with } \\
\text { pediatrics/fear of making mistakes, cultural: children are more 'valuable' than 'old" } \\
\text { people in some people's eyes" } \\
\text { "Most people have a deeper emotional response to injured children" } \\
\text { "Everyone can handle adult trauma because as we get older, we are expected to } \\
\text { get hurt and sick, but not our children" } \\
\text { "Fear or ruining someone's WHOLE life, before they have had a chance to live it" }\end{array}$ \\
\hline Experience/exposure & $\begin{array}{l}\text { "Due to rarity of peds trauma and the fragility of children workers are often shocked } \\
\text { with this" } \\
\text { "Lack of experience or confidence" } \\
\text { "Small percentage of our patients" } \\
\text { "Anxiety of not feeling proficient or experienced enough" } \\
\text { "Infrequent exposure to pediatric clinical cases making the clinician feel insecure" }\end{array}$ \\
\hline Family emotional response & $\begin{array}{l}\text { "Bystanders and parents watching make doing your job difficult. EMS providers are } \\
\text { already stressed and then you add a screaming mother, father or sibling" } \\
\text { "Family on scene causing stress we don't normally have" } \\
\text { "Family presence can also increase the stress level as expectations become very } \\
\text { high when dealing with people's children" }\end{array}$ \\
\hline Child's emotional response & $\begin{array}{l}\text { "Crying! It's so difficult to calm an injured child, or ignore the distraction of an upset } \\
\text { child" } \\
\text { "Children's fears can exacerbate their perception of the severity of injury and this } \\
\text { excites the parents" } \\
\text { "Kids cry more in general and it may be due to fear as well as pain" }\end{array}$ \\
\hline Rapid decompensation & $\begin{array}{l}\text { "Need to act quickly paralyses decision choices" } \\
\text { "Underestimation of non-visible blood loss since kids compensate so well (vital } \\
\text { signs not as sensitive as in adults)" } \\
\text { "Children can have minimal symptoms from a trauma and then crash quickly } \\
\text { causing a constant stress during treatment and transport" }\end{array}$ \\
\hline
\end{tabular}
causing a constant stress during treatment and transport"

judgement. The second most common cause of heightened stress or anxiety involved personal and societal pressures brought about by seeing an innocent child injured and the fact that the child's whole life could be impacted by the outcome of this event.

Previous studies by our group and others have linked provider stress and/or anxiety to safety events in out-of-hospital paediatric care. Focus groups from earlier phases of the CSI-EMS study identified anxiety as a significant factor in paediatric care. ${ }^{10}$ A qualitative study of EMS providers by Cushman $e t a l^{18}$ found that stress and anxiety related to lack of experience contributed to errors, and of some concern, they found that in such cases, providers were reluctant to report or discuss their errors. Other studies suggest that errors contribute to provider anxiety and burnout, creating a potential downward spiral of errors leading to a higher likelihood of future errors through increased anxiety. ${ }^{19} 20$ This literature suggests that stress is detrimental to providers' wellbeing, and it may also be detrimental to patient safety.

What is the mechanism by which stress affects patient safety? The human factors and neuroscience literature have described a mixed picture about the effect of anxiety on cognition and performance. According to the Yerkes-Dodson Law first described in $1908,{ }^{21}$ cognitive performance is poor with low or high levels of arousal/stress. One recent study that used a small electric shock to cause anxiety suggested that anxiety may 
Figure 1 Concepts are arranged from contributors proximal to the provider (left), expanding to influences distal from the provider (right). Bold font indicates a key concept. Bullet points indicate examples of the concept.

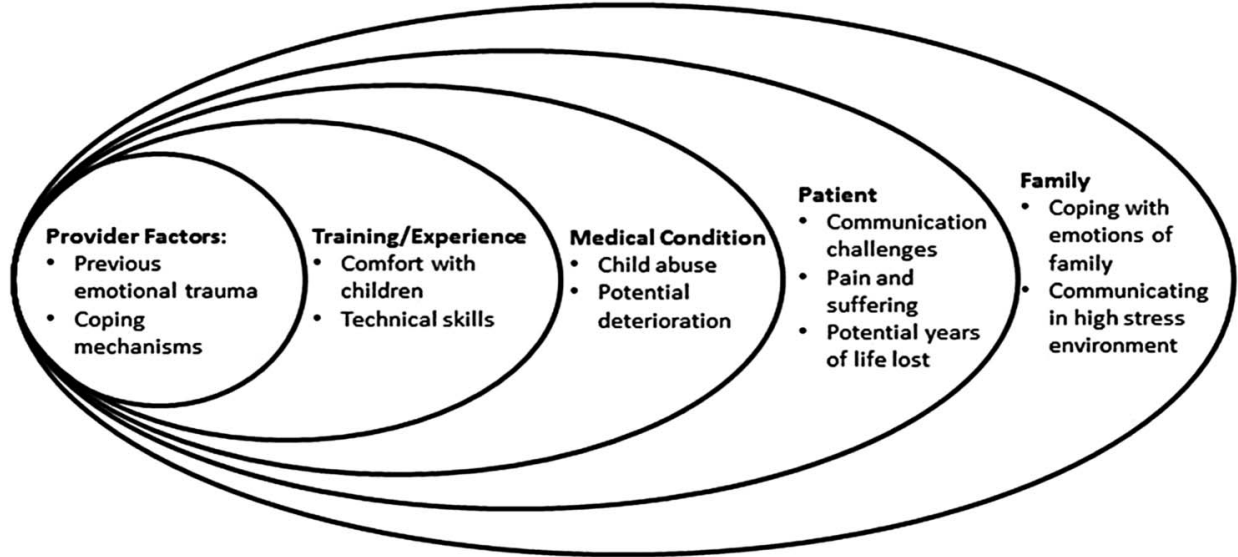

reduce working memory for spatial and verbal tasks which could be a potential mechanism for high anxiety negatively influencing decision-making and performance. $^{22}$ Similarly, anxiety and cortisol were elevated in paramedics experiencing high and low stress simulations with one confederate helper and elevations in both affected paramedic performance. ${ }^{23}$ However, a study among emergency medicine residents suggests that the relationship between stress/anxiety and performance may be even more complicated depending on the level of stress and the experience level of the learner. ${ }^{24}$ Thus, the relationship between anxiety and performance is complex and not fully understood.

The evidence is growing that provider stress is an important factor to understand and address for provider and patient well-being. To the best of our knowledge, the CSI-EMS project is the largest study of out-of-hospital providers' perceptions of potential contributors to safety events in the out-of-hospital care of children. This qualitative survey represented EMS professionals across the USA. The use of free text survey responses allowed for a rich and unbiased description of EMS providers' experiences. Owing to the size of our study, we were able to identify a wide range of contributors to EMS stress and anxiety and were able to discern that the causes of EMS provider stress and anxiety go beyond lack of experience or insufficient knowledge, originating commonly from features that are inherent to the nature of children. However, the study has important limitations. The study focuses on perceptions by EMS providers rather than observed outcomes. Perceptions of experienced clinicians in the field are critically important to our understanding of patient safety as they are a blend of frequency of events, severity of consequences, and insights into potential mechanisms, causes and preventability. However, it is difficult to know the degree of stress or anxiety and specifically whether and how it actually impacts the EMS care of paediatric emergencies. While our survey sample was geographically diverse, representing 44 of 50 states $(88 \%)$ in the USA, we had strong representation from the Northwest, Midwest and Northeast and less from California and the Southeast, which could limit the generalisability of our results to these areas as well as other areas of the world. Although EMS systems and context vary worldwide, it is most likely that the anxiety caused by the inherent nature of children is shared across settings. Finally, attrition occurred across the course of survey rounds with $66 \%$ of respondents completing all three surveys; however, the general demographic distribution of respondents remained stable across survey rounds.

Further research is needed to explore the physiological effects of provider stress and anxiety during complex psychomotor processes and to identify how these interplay with care delivery. Specifically for out-of-hospital care, the results of this study suggest that paediatric trauma, respiratory distress, cardiac arrest and non-accidental trauma are clinical areas that are in particular need for the development and testing of interventions such as simulation training, personnel debriefing and cognitive aids which may mitigate the effect of stress at the point of care. Efforts to improve patient safety in prehospital paediatric care will most likely have the greatest impact if these provider-level factors are considered.

\section{Author affiliations}

${ }^{1}$ Department of Obstetrics and Gynecology, Oregon Health and Science University, Portland, Oregon, USA

${ }^{2}$ Department of Emergency Medicine, Oregon Health and Science University, Portland, Oregon, USA

${ }^{3}$ Department of Medical Informatics and Clinical Epidemiology, Oregon Health and Science University, Portland, Oregon, USA

${ }^{4}$ Oregon Health and Science University-Portland State University School of Public Health and Preventive Medicine, Portland, Oregon, USA

${ }^{5}$ Department of Psychology, Portland State University, Portland, Oregon, USA

${ }^{6}$ Oregon Rural Practice-based Research Network, Oregon Health and Science University, Portland, Oregon, USA

${ }^{7}$ Department of Pediatrics and Emergency Medicine, University of British Columbia, Vancouver, British Columbia, Canada

${ }^{8}$ Oregon Health Authority, Public Health Division, Portland, Oregon, USA

Contributors J-MG contributed to the conception and design of the study, development of survey tools, recruitment of participants and survey distribution, acquisition of the data, qualitative analysis and interpretation of the data, drafting and revising the article for important content and final approval of the submitted manuscript. MH contributed to interpretation and analysis of the data for the study, drafting and revising the article for 
important content, and final approval of the submitted manuscript. KOB contributed to the design of the study, development and validation of survey instruments, qualitative analysis of data and critical review of the manuscript. CD contributed to the development of data collection tools, collection, validation and qualitative analysis of data and provided critical review of the manuscript. GM, WL, PE and JJ contributed to the design of the study, development of survey instruments, recruitment of participants, validation, and analysis of data, and critical review of the manuscript.

Funding This work was supported by the National Institute of Child Health and Human Development grant 'Epidemiology of Preventable Safety Events in Pre-hospital EMS of Children'. R01HD062478-04.

Disclaimer The content is solely the responsibility of the authors and does not represent the official views of the National Institute of Child Health and Human Development, or the National Institutes of Health.

Competing interests None declared.

Ethics approval This study was approved by the Oregon Health and Science University Institutional Review Board (IRB\# 6942).

Provenance and peer review Not commissioned; externally peer reviewed.

Data sharing statement Relevant anonymised data are available on reasonable request from the corresponding author.

Open Access This is an Open Access article distributed in accordance with the Creative Commons Attribution Non Commercial (CC BY-NC 4.0) license, which permits others to distribute, remix, adapt, build upon this work noncommercially, and license their derivative works on different terms, provided the original work is properly cited and the use is non-commercial. See: http:// creativecommons.org/licenses/by-nc/4.0/

\section{REFERENCES}

1. De Boer J, Lok A, Van't Verlaat EV, et al. Work-related critical incidents in hospital-based health care providers and the risk of post-traumatic stress symptoms, anxiety, and depression: a meta-analysis. Soc Sci Med 2011;73:316-26.

2. Alexander DA, Klein S. Ambulance personnel and critical incidents: impact of accident and emergency work on mental health and emotional well-being. Br J Psychiatry 2001;178:76-81.

3. Jonsson A, Segesten K, Mattsson B. Post-traumatic stress among Swedish ambulance personnel. Emerg Med J 2003;20:79-84.

4. Berger W, Coutinho ES, Figueira I, et al. Rescuers at risk: a systematic review and meta-regression analysis of the worldwide current prevalence and correlates of PTSD in rescue workers. Soc Psychiatry Psychiatr Epidemiol 2012;47:1001-11.

5. Ravenscroft T. Going critical: survey of occupational stress factors in accident and emergency staff in the London ambulance service. London, UK: GMB/Apex/and T\&G Unions, 1994.
6. Rodgers IM. A five year study comparing early retirements on medical grounds in ambulance personnel with those in other groups of health service staff. Part II: causes of retirements. Occup Med 1998;48:119-32.

7. Ramirez AJ, Graham J, Richards MA. Mental health of hospital consultants: the effects of stress and satisfaction at work. Lancet 1996;347:724-8.

8. Nichols P. Learning from error: identifying contributory causes of medication errors in an Australian hospital. Med J Aust 2008;188:276-9.

9. LeBlanc VR, MacDonald RC, McArthur B, et al. Paramedic performance in calculating drug dosages following stressful scenarios in a human patient simulator. Prehosp Emerg Care 2005;9:439-44.

10. Cottrell EK, O'Brien $\mathrm{K}$, Curry $\mathrm{M}$, et al. Understanding safety in prehospital emergency medical services for children. Prehosp Emerg Care 2014;18:350-8.

11. Guise JM, Meckler G, O'Brien $\mathrm{K}$, et al. Patient safety perceptions in pediatric out-of-hospital emergency care: children's safety initiative. $J$ Pediatr 2015;167:1143-8.e1.

12. Hansen M, Meckler G, O'Brien K, et al. Pediatric airway management and prehospital patient safety: results of a national Delphi survey by the Children's Safety Initiative- Emergency Medical Services for Children. Pediatr Emerg Care 2015;19:287-91.

13. Wright G. Delphi: a reevaluation of research and theory. Tech Forecast Soc Change 1991;39:235-51.

14. Miles MB, Huberman M. Qualitative data analysis: a sourcebook of new methods. 2nd edn. Beverly Hills, CA: Sage Publications, 1994

15. Corbin J, Strauss A. Grounded theory research: procedures, canons and evaluative criteria. Qual Soc 1990;13:19.

16. Bronfenbrenner U. The ecology of human development: experiments by nature and design. Cambridge, MA: Harvard University Press, 1979.

17. Glass TA, McAtee MJ. Behavioral science at the crossroads in public health: extending horizons, envisioning the future. Soc Sci Med 2006;62:1650-71.

18. Cushman JT, Fairbanks RJ, O'Gara KG, et al. Ambulance personne perceptions of near misses and adverse events in pediatric patients. Prehosp Emerg Care 2010;14:477-84

19. Shanafelt TD, Balch CM, Bechamps G, et al. Burnout and medical errors among American surgeons. Ann Surg 2010;251:995-1000.

20. Gallagher TH, Waterman AD, Ebers AG, et al. Patients' and physicians' attitudes regarding the disclosure of medical error. JAMA 2003;289:1001-7.

21. Yerkes RM, Dodson JD. The relation of strength and stimulus to rapidity of habit-formation. J Comp Neur Psych 1908;18:459-82.

22. Vytal KE, Cornwell BR, Letkiewicz AM, et al. The complex interaction between anxiety and cognition: insight from spatial and verbal working memory. Front Hum Neurosci 2013;7:93.

23. LeBlanc VR, Regehr C, Tavares W, et al. The impact of stress on paramedic performance during simulated critical events. Prehosp Disaster Med 2012;27:369-74.

24. LeBlanc VR. The effects of acute stress on performance: implications for health professions education. Acad Med 2009;84 (Suppl 10):S24-33. 